\title{
Pyroxene low-temperature plasticity and fragmentation as a record of seismic stress evolution in the lower crust
}

Campbell, L

http://hdl.handle.net/10026.1/15903

10.5194/egusphere-egu2020-7380

All content in PEARL is protected by copyright law. Author manuscripts are made available in accordance with publisher policies. Please cite only the published version using the details provided on the item record or document. In the absence of an open licence (e.g. Creative Commons), permissions for further reuse of content should be sought from the publisher or author. 
EGU2020-7380

https://doi.org/10.5194/egusphere-egu2020-7380

EGU General Assembly 2020

(c) Author(s) 2020. This work is distributed under

the Creative Commons Attribution 4.0 License.

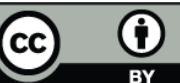

\title{
Pyroxene low-temperature plasticity and fragmentation as a record of seismic stress evolution in the lower crust
}

\author{
Lucy Campbell ${ }^{1}$ and Luca Menegon ${ }^{1,2}$ \\ ${ }^{1}$ School of Geography, Earth and Environmental Sciences, Plymouth University, Plymouth, UK \\ ${ }^{2}$ The Njord Centre, University of Oslo, Oslo, Norway
}

Seismic rupture of the lower continental crust requires a high failure stress, given large lithostatic stresses and potentially strong rheologies. Several mechanisms have been proposed to generate high stresses at depth, including local amplification of stress heterogeneities driven by the geometry and rheological contrast within a shear zone network. High dynamic stresses are additionally associated with the subsequent slip event, driven by propagation of the rupture tips. In the brittle upper crust, fracturing of the damage zone is the typical response to high stress, but in the lower crust, the evolution of combined crystal plastic and brittle deformation may be used to constrain in more detail the stress history of rupture, as well as additonal parameters of the deformation environment. It is crucial to understand these deep crustal seismic deformation mechanisms both along the fault and in the wall rock, as coseismic damage is an important (and sometimes the only) method of significantly weakening anhydrous and metastable lower crust, whether by grain size reduction or by fluid redistribution.

A detailed study of pyroxene microstructures are used here to characterise the short-term evolution of high stress deformation experienced on the initiation of lower crustal earthquake rupture. These pyroxenes are sampled from the pseudotachylyte-bearing fault planes and damage zones of lower crustal earthquakes linked to local stress amplifications within a viscous shear zone network, recorded in an exhumed granulite-facies section in Lofoten, northern Norway. In orthopyroxene, initial low-temperature plasticity is overtaken by pulverisation-style fragmentation, generating potential pathways for hydration and reaction. In clinopyroxene, lowtemperature plasticity remains dominant throughout but the microstructural style changes rapidly through the pre- and co-seismic periods from twinning to undulose extinction and finally the formation of low angle boundaries. We present here an important record of lower crustal shortterm stress evolution along seismogenic faults. 